\title{
Application of Numerical Techniques to Tsunami Simulation
}

[Noverina Alfiany, Masaji Watanabe]

\begin{abstract}
This study shows the practical application of numerical techniques for tsunami simulation. Our techniques were tested against a model problem of flow with linear bottom friction over a parabolic bottom topography. A governing system of partial differential equations was spatially discretized over a triangular mesh. Standard ODE solvers were applied to the resultant system of ordinary differential equations for the horizontal fluxes and the wave height. At each time step, each node was tested to determine whether it was "wet" or "dry", according to criteria on the total depth. An initial displacement was set according to source fault plane generated by other authors. Our techniques were applied to the Mentawai 2010 tsunami simulation and the Indian Ocean 2004 tsunami simulation.
\end{abstract}

Keywords - Numerical techniques, parabolic bottom topography, standard ODE solver, tsunami simulation.

\section{Introduction}

Waves are the change of the physical quantity which travels from the source locations to another surrounding area. Water waves are classified according to the mechanism of their generation or based on their shape and characteristics [1]. The causative factors and generating sources of water waves include gravity, tide, wind, earthquakes, landslide, iceberg collapses, and underwater volcanic activities, etc. Tsunami is one of the water waves generated by earthquakes or underwater shocks.

Recent devastating tsunamis include the Indian Ocean tsunami which occurred on December $26^{\text {th }}, 2004$, and the Great East Japan earthquake tsunami which occurred on March $11^{\text {th }}, 2011$. The Indian Ocean earthquake recorded the largest magnitude in the last half-century. Studies estimated the moment magnitude $\left(\mathrm{M}_{\mathrm{w}}\right)$ of the earthquake between 9.0 and 9.3. The tsunami generated by this earthquake was the most devastating and deadly one, with more than 200,000 fatalities along the coasts of the Indian Ocean [2]. The earthquake shook at the Pacific coast of Tohoku with moment magnitude $M_{w}$ 9.0-9.1 and generated a tsunami which caused more than eighteen thousand fatalities and severe destructions including the core meltdown at Fukushima No. 1 nuclear power plant. The field surveys reported tsunami run-up heights exceeding $30 \mathrm{~m}$ with the water level gradually rising up $2 \mathrm{~m}$ during the first 10 minutes [3].

Noverina Alfiany

Graduate School of Environmental and Life Science, Okayama University Japan

Masaji Watanabe

Okayama University

Japan
Those previous reports show that the study of tsunami generations and propagations are crucial to establishing better disaster countermeasures for future tsunami events. The numerical study of the tsunamis, through the analysis of the shallow water equations, can provide the outcomes which describe tsunami characteristics and effects. Moreover, outcomes from numerical studies can lead to the establishment of early warning systems for evacuation. A tsunami wave which is described mathematically in terms of its amplitude, wavelength and propagation speed. The wave height expressed in terms of solutions of the appropriate wave equations, linear or nonlinear partial differential equations [1]. Analyses of propagation and wave height of tsunamis are based on momentum equations and continuity equations. Those systems of partial differential equations are solved numerically for simulation of tsunami attacks.

An earthquake with $M_{w} 7.8$ and epicenter $20 \mathrm{~km}$ below the surface occurred at the Mentawai Islands Regency, Indonesia on October $25^{\text {th }}, 2010$. The Mentawai Islands earthquake generated the much larger tsunami than expected from its seismic magnitude [4]. Furthermore, the Sumatra-Andaman earthquake occurred at 7:28:53 WIB (Western Indonesian Time) 2004 with the epicenter $30 \mathrm{~km}$ below the surface, and generated the Indian Ocean tsunami which has the most destructive power. The effects of this event spread unto the countries located far from the epicenter and caused a terrible destruction to the location near the epicenter i.e. the Aceh Province, Indonesia. Numerical techniques for moving boundary [5]-[6] was incorporated into the previous study [7].

A governing system of partial differential equations was reduced to a system of ordinary differential equation with spatial discretization over a triangular mesh. ODE solvers were applied to the resultant system of ODE's in conjunction with a moving boundary technique. Our techniques were tested with a problem for which an exact solution was available. The Mentawai 2010 tsunami and the Indian Ocean 2004 tsunami were analyzed with those numerical techniques.

\section{Finite Element Analysis}

\section{A. Description of Governing Equations}

The nonlinear shallow water equations (1)-(3) were solved numerically for simulation of tsunami wave propagation [8]

$\frac{\partial \eta}{\partial t}+\left(\frac{\partial M}{\partial t}+\frac{\partial N}{\partial t}\right)=0$

$\frac{\partial M}{\partial t}+\frac{\partial}{\partial x}\left(\frac{M^{2}}{H}\right)+\frac{\partial}{\partial y}\left(\frac{M N}{H}\right)+g H \frac{\partial \eta}{\partial x}+f_{x}=0$,

$\frac{\partial N}{\partial t}+\frac{\partial}{\partial x}\left(\frac{M N}{H}\right)+\frac{\partial}{\partial y}\left(\frac{N^{2}}{H}\right)+g H \frac{\partial \eta}{\partial y}+f_{y}=0$.

Here, $H(x, y, t)$ is the total depth where $H(x, y, t)=$ $h(x, y)+\eta(x, y, t), h(x, y)$ is sea depth and $\eta(x, y, t)$ is water surface elevation from the mean sea level. The 
constant $g$ is the gravitational acceleration. Functions $M(x, y, t)$ and $N(x, y, t)$ are the discharge fluxes, the integrations of $x$-component of the velocity $u$, and of $y$ component of the velocity $v$, respectively, that is

$$
M(x, y, t)=\int_{-h}^{\eta} u d z, N(x, y, t)=\int_{-h}^{\eta} v d z
$$

Terms $f_{x}$ and $f_{y}$ are the $x$-component and $y$-component of the bottom friction, respectively

$$
f_{x}=\frac{g n^{2}}{H^{\frac{7}{3}}} \sqrt{M^{2}+N^{2}}, f_{y}=\frac{g n^{2}}{H^{\frac{7}{3}}} \sqrt{M^{2}+N^{2}},
$$

where $n$ is the Manning roughness coefficient.

\section{B. Illustration of Numerical Techniques}

Let a domain in the $x y$-plane be subdivided into triangular elements with total nodes $m$ and total elements $k$. The basis function associated with the $i^{\text {th }}$ node $\left(x_{i}, y_{i}\right)$ is a piecewise linear continuous function over the domain, which satisfies

$$
\Phi_{j}\left(x_{i}, y_{i}\right)=\delta_{i j}=\left\{\begin{array}{ll}
1 & \text { if } i=j \\
0 & \text { if } i \neq j
\end{array} .\right.
$$

Suppose that the functions $M(x, y, t), N(x, y, t), \eta(x, y, t)$ and $h(x, y)$ are approximated by linear combinations of the basis function $\Phi_{j}$

$$
\begin{aligned}
& M(x, y, t)=\sum_{j=1}^{m} M_{j}(t) \Phi_{j}(x, y), \\
& N(x, y, t)=\sum_{j=1}^{m} N_{j}(t) \Phi_{j}(x, y), \\
& \eta(x, y, t)=\sum_{j=1}^{m} \eta_{j}(t) \Phi_{j}(x, y), \\
& h(x, y)=\sum_{j=1}^{m} h_{j} \Phi_{j}(x, y) .
\end{aligned}
$$

Here $M_{j}, N_{j}, \eta_{j}$, and $h_{j}$ are unknown coefficients.

The system equations (11)-(13) are obtained by substituting equations (7)-(10) into the system equations (1)(3), and by setting $(x, y)=\left(x_{i}, y_{i}\right)$

$\frac{d \eta_{i}}{d t}=-\left(\frac{\partial M}{\partial x}+\frac{\partial N}{\partial y}\right)$,

$\frac{d M_{i}}{d t}=-\frac{\partial}{\partial x}\left(\frac{M^{2}}{h_{i}+\eta_{i}}\right)-\frac{\partial}{\partial y}\left(\frac{M N}{h_{i}+\eta_{i}}\right)-g \frac{\partial \eta}{\partial x}\left(h_{i}+\eta_{i}\right)-f_{x}$,

$\frac{d N_{i}}{d t}=-\frac{\partial}{\partial x}\left(\frac{M N}{h_{i}+\eta_{i}}\right)-\frac{\partial}{\partial y}\left(\frac{N^{2}}{h_{i}+\eta_{i}}\right)-g \frac{\partial \eta}{\partial y}\left(h_{i}+\eta_{i}\right)-f_{y}$,

where

$$
\begin{aligned}
& f_{x}=\frac{g n^{2}}{\left(h_{i}+\eta_{i}\right)^{\frac{7}{3}}} M_{i} \sqrt{M_{i}+N_{i}}, \\
& f_{y}=\frac{g n^{2}}{\left(h_{i}+\eta_{i}\right)^{\frac{7}{3}}} N_{i} \sqrt{M_{i}+N_{i}} .
\end{aligned}
$$

The partial derivatives on the right-hand sides of the equations (11)-(13) are evaluated at $(x, y)=\left(x_{i}, y_{i}\right)$, and approximated by their weighted averages over the elements associated with the common node $\left(x_{i}, y_{i}\right)$.

\section{Numerical Techniques Formulation}

The specific form of the piecewise linear function $\phi_{i}$, which satisfies $\phi_{j}\left(x_{i}, y_{i}\right)=\delta_{i j}$, will be derived for a triangular element. The linear function with constants $c_{1}, c_{2}$, $c_{3}$ is expressed by [9]

$u(x, y)=c_{1}+c_{2} x+c_{3} y$.

Function (16) is defined for nodes $\left(x_{i}, y_{i}\right),\left(x_{j}, y_{j}\right)$ and $\left(x_{k}, y_{k}\right)$ of element $e$, such that satisfies the conditions $u\left(x_{i}, y_{i}\right)=u_{i}, u\left(x_{j}, y_{j}\right)=u_{j}, u\left(x_{k}, y_{k}\right)=u_{k}$, where $\left(x_{i}, y_{i}\right),\left(x_{j}, y_{j}\right),\left(x_{k}, y_{k}\right)$ are the coordinates of the three vertices of triangular element $e$. In each element, $u$ is expressed by $u(x, y)=u_{i} \phi_{i}^{(e)}\left(x_{i}, y_{i}\right)+u_{j} \phi_{j}^{(e)}\left(x_{j}, y_{j}\right)+u_{k} \phi_{k}^{(e)}\left(x_{k}, y_{k}\right) .(17)$ Here, $\phi_{i}^{(e)}, \phi_{j}^{(e)}$, and $\phi_{k}^{(e)}$ are piecewise linear functions for the triangular elements given by

$\phi_{i}^{(e)}=\frac{1}{2 A_{e}}\left(\alpha_{i}+\beta_{i} x+\gamma_{i} y\right)$,

$\phi_{j}^{(e)}=\frac{1}{2 A_{e}}\left(\alpha_{j}+\beta_{j} x+\gamma_{j} y\right)$,

$\phi_{k}^{(e)}=\frac{1}{2 A_{e}}\left(\alpha_{k}+\beta_{k} x+\gamma_{k} y\right)$.

Here $A_{e}$ is the area of the triangle given by

$A_{e}=\frac{x_{i}\left(y_{j}-y_{k}\right)+x_{j}\left(y_{k}-y_{i}\right)+x_{k}\left(y_{i}-y_{j}\right)}{2}$.

Constants $\alpha_{i}, \beta_{i}, \gamma_{i}$ are expressed by $\alpha_{i}=x_{j} y_{k}-x_{k} y_{j}$, $\beta_{i}=y_{j}-y_{k}$ and $\gamma_{i}=x_{k}-x_{j}$. Index $i, j, k$ satisfies $i \neq j \neq k$ and $i, j, k$ transpose in a natural order (changes order on clockwise).

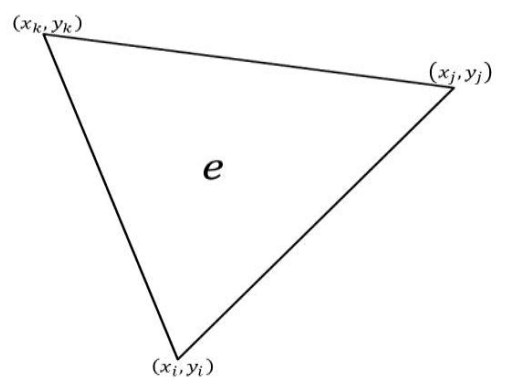

Figure 1: Three vertices of triangular element $e$.

The partial derivatives of any functions $u$ with respect to $x$ and $y$ by the approximation (17) is expressed with

$\frac{\partial u}{\partial x}=u_{i} \frac{y_{j}-y_{k}}{2 A_{e}}+u_{j} \frac{y_{k}-y_{i}}{2 A_{e}}+u_{k} \frac{y_{i}-y_{j}}{2 A_{e}}$,

$\frac{\partial u}{\partial y}=u_{i} \frac{x_{k}-x_{j}}{2 A_{e}}+u_{j} \frac{x_{i}-x_{k}}{2 A_{e}}+u_{k} \frac{x_{j}-x_{i}}{2 A_{e}}$.

The approximate values of $\frac{\partial u}{\partial x}$ and $\frac{\partial u}{\partial y}$ at the $i^{\text {th }}$ node, are the weighted average values of their partial derivations over the elements which corresponding to the $i^{\text {th }}$ node, given by

$\left(\frac{\partial u}{\partial x}\right)_{i}=\frac{1}{\sum_{k=1}^{l}\left(A_{e}\right)_{k}} \sum_{k=1}^{l}\left(A_{e}\right)_{k}\left(\frac{\partial u}{\partial x}\right)^{(k)}$,

$\left(\frac{\partial u}{\partial y}\right)_{i}=\frac{1}{\sum_{k=1}^{l}\left(A_{e}\right)_{k}} \sum_{k=1}^{l}\left(A_{e}\right)_{k}\left(\frac{\partial u}{\partial y}\right)^{(k)}$.

Here, $\left(\frac{\partial u}{\partial x}\right)^{(k)}$ is an approximate value of the partial derivative $\left(\frac{\partial u}{\partial x}\right)$ in the $k$-th element.

The numerical techniques developed in the previous studies were applied for a discretization of the system of partial differential equations to the system of ordinary differential equations (ODE). Hence, those systems of ordinary differential equations were solved numerically with ODE solvers. In particular, the fourth order AdamsBashforth-Moulton predictor-corrector in PECE mode in conjunction with the Runge-Kutta method was employed to generate the values of approximation solutions at the first three steps [10]. 


\section{Verification of Numerical Techniques}

\section{A. Wet and Dry Scheme}

In the simulation of moving boundary shallow water equations, what is called, wet and dry scheme [5]-[6] were applied. In a simulation, what is called, wet and dry conditions at each node, were checked at the end of each full-time step with step length $\Delta t$. Suppose that $H_{i}=$ $\left(h_{i}+\eta_{i}\right)$ is the total depth at node $i$. If $H_{i}>0$ then node $i$ is called wet node. It is called dry node if $H_{i} \leq 0$. The current velocities at dry nodes are set to zero, the water elevation is set to $\eta_{i}=-h_{i}$.

Let triangular element $e$ has three nodes, $i, j$, and $k$. Functions $H_{i}=\left(h_{i}+\eta_{i}\right), H_{j}=\left(h_{j}+\eta_{j}\right)$ and $H_{k}=$ $\left(h_{k}+\eta_{k}\right)$ are total water depth at node $i, j, k$, respectively.

1. If all of the nodes satisfies $H_{i}>0, H_{j}>0$ and $H_{k}>0$, element $e$ is called the wet element or said to be underwater.

2. At least one of $H_{i} \leq 0$ or $H_{j} \leq 0$ or $H_{k} \leq 0$ is satisfied, then element $e$ is called dry element.

Application wet and dry scheme to the numerical simulation of moving boundary shallow water equations requires changing conditions on both nodes and elements. Where with the moving boundary scheme some elements are wet for part of the time and dry for another part of the time.

If at least one of the three wet nodes $i, j$ or $k$ of wet element $e$ have the non-positive total water depth at the end of the time step $\Delta t$, then the total water depth and wave velocity are set to zero. Nodes which satisfy that condition are regarded as dry nodes. Hence, the previously wet element $e$ is changed from a wet to a dry element. The values of the variables, velocities $U, V$ and water elevation $\eta$, are obtained from the generating values of the approximate solutions by Adam-Bashforth-Moulton predictor-corrector in conjunction with Runge-Kutta.

Furthermore, a process of determining the change of dry element to wet element is decided for every dry element $e$ which contains only one dry node and two wet nodes, at the end of time step $\Delta t$. Let $i, j$ or $k$ are nodes on a dry element $e$, where $H_{i}=\left(h_{i}+\eta_{i}\right) \leq 0, H_{j}=\left(h_{j}+\eta_{j}\right)>0$ and $H_{k}=\left(h_{k}+\eta_{k}\right)>0$. In other words, node $i$ is dry, and nodes $j, k$ are wet. Suppose that the water elevation of the two wet nodes, $\eta_{j}$ for node $j$ and $\eta_{k}$ for node $k$, was calculated and found that $\eta_{j}>\eta_{k}$. A formulation to computed water elevation $\eta_{i}$ at time $t+\Delta t$ is given by

$$
\begin{aligned}
& \eta_{i}^{t+\Delta t}=\eta_{j}^{t+\Delta t}-\frac{\Delta x}{g}\left(\frac{U_{j}^{t+\Delta t}-U_{j}^{t}}{\Delta t}+\tau_{j} U_{j}^{t+\Delta t}\right)-\frac{\Delta y}{g}\left(\frac{V_{j}^{t+\Delta t}-V_{j}^{t}}{\Delta t}+\right. \\
& \left.\tau_{j} V_{j}^{t+\Delta t}\right) .
\end{aligned}
$$

Here, $\Delta x=x_{i}-x_{j}, \Delta y=y_{i}-y_{j}, U_{j}$ and $V_{j}$ are the velocities at node $j$, the constant $\tau$ is the bottom friction coefficient and $g$ is the gravity acceleration coefficient. If $\eta_{i}^{t+\Delta t}>h_{i}$, then node $i$ becomes wet, otherwise node $i$ stays dry. If node $i$ becomes wet, then the velocities at node $i$ are set equal to the velocities at node $j$ and element $e$ become wet.

\section{B. Comparison of Exact Solution and Numerical Solution}

Exact solutions of the two-dimensional nonlinear shallow water equations, involving linear bottom friction for flow above parabolic bottom topography were reported [5]-[6]. The characteristic feature of those solutions involves moving shoreline. Consider the case where the motion of shallow water in a basin is governed by the equations [5],[11]

$\frac{\partial \varsigma}{\partial t}+\frac{\partial(h+\varsigma) U}{\partial x}+\frac{\partial(h+\varsigma) V}{\partial y}=0$,

$\frac{\partial U}{\partial t}+U \frac{\partial U}{\partial x}+V \frac{\partial U}{\partial y}+\tau U+g \frac{\partial \varsigma}{\partial x}=0$,

$\frac{\partial U}{\partial t}+U \frac{\partial U}{\partial x}+V \frac{\partial U}{\partial y}+\tau U+g \frac{\partial \varsigma}{\partial x}=0$,
$\frac{\partial V}{\partial t}+U \frac{\partial V}{\partial x}+V \frac{\partial V}{\partial y}+\tau V+g \frac{\partial \varsigma}{\partial y}=0$.

Here, $\varsigma(x, y, t)$ is the height of the water surface above mean water level, the water surface $z=-h(x, y)$ is the bottom surface, $U(x, y, t)$ and $V(x, y, t)$ are the depth-averaged $x$ and $y$ velocity components, respectively. The constant $\tau$ is the bottom friction parameter, and constant $g$ is the gravity acceleration.

Assume that flow takes place in the parabolic canal

$h(x, y)=h_{0}\left(1-\frac{x^{2}}{a^{2}}\right)$,

where $h_{0}$ and $a$ are positive constants. Exact solutions for $\tau<\sqrt{\frac{8 g h_{0}}{a^{2}}}$ are given by

$U(x, y, t)=B e^{-\frac{\tau t}{2}} \sin (s t)$,

$V(x, y, t)=0$,

$\varsigma(x, y, t)=\frac{a^{2} B^{2} e^{-\tau t}}{8 g^{2} h_{0}}\left[-s \tau \sin (2 s t)+\left(\frac{\tau^{2}}{4}-s^{2}\right) \cos (2 s t)\right]-$ $\frac{B^{2} e^{-\tau t}}{4 g}-x\left\{\frac{e^{-\frac{\tau t}{2}}}{g}\left[B s \cos (s t)+\frac{\tau B}{2} \sin (s t)\right]\right\}$.

Here, $s=\frac{\sqrt{p^{2}-\tau^{2}}}{2}$ and $p=\sqrt{\frac{8 g h_{0}}{a^{2}}}$. Numerical techniques of finite element analysis were applied to system equations (26)-(28), it yields

$\frac{\partial \varsigma}{\partial t}=-\frac{\partial \varsigma}{\partial x} u+\frac{2 h_{0} x}{a^{2}} u$,
$\frac{\partial u}{\partial t}=-\left(\tau u+g \frac{\partial \varsigma}{\partial x}\right)$,
$\frac{\partial v}{\partial t}=-g \frac{\partial \varsigma}{\partial y}$.

System equations (33)-(35) were used to obtained the numerical solutions by our numerical techniques.

Initial conditions are given by $u\left(t_{0}\right)=B e^{-\frac{\tau t}{2}} \sin \left(s t_{0}\right)$, $v\left(t_{0}\right)=0$, and $\varsigma\left(t_{0}\right)=\varsigma_{0}\left(t_{0}\right)+x \varsigma_{1}\left(t_{0}\right)$ where

$S_{0}\left(t_{0}\right)=$
$\frac{a^{2} B^{2} e^{-\tau t_{0}}}{8 g^{2} h_{0}}\left(-s \tau \sin \left(2 s t_{0}\right)+\left(\frac{\tau^{2}}{4}-s^{2}\right) \cos \left(2 s t_{0}\right)\right)-\frac{B^{2} e^{-\tau t_{0}}}{4 g}$,

$S_{1}\left(t_{0}\right)=-\frac{e^{-\frac{\tau t_{0}}{2}}}{g}\left(B s \cos \left(s t_{0}\right)+\frac{\tau B}{2} \sin \left(s t_{0}\right)\right)$.

Both solutions, exact and numerical solutions, were considered in a parabolic canal which constants value $a=3$ $\mathrm{km}, h_{0}=10 \mathrm{~m}$ for motion in which $B=5 \mathrm{~m} \mathrm{~s}^{-1}$. The solutions for displacement of the fluid over a parabolic canal are the exact solutions obtained [5] for $\tau=0.001 \mathrm{~s}^{-1}$.

Fig. 2 (a) and (b) show profiles of the initial water surface for numerical techniques and exact solutions, respectively. Fig. 3 (a), (b), (c) and (d) show the comparison between 
Proc. of The Seventh Intl. Conf. on Advances in Civil, Structural and Environmental Engineering - ACSEE 2018 Copyright (C) Institute of Research Engineers and Doctors, USA. All rights reserved.

ISBN: 978-1-63248-158-0 doi: 10.15224/978-1-63248-158-0-28

numerical techniques (blue line) and exact solutions (green line) profiles of water surface for $t=200$ seconds, $t=400$ seconds, $t=600$ seconds and $t=800$ seconds. The comparison between exact solution values and numerical solution values shows an acceptable agreement between both solutions for every time step up to 800 seconds. Numerical solutions for water elevation $\varsigma$ starts to increase enormously around the water boundary and become uncontrollable. So far we have not found a reason for the collapse.

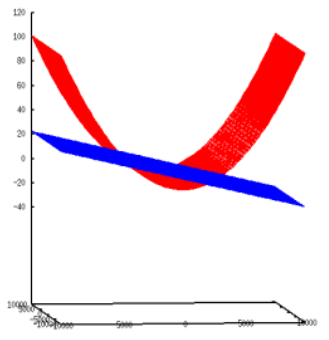

(a) Numerical techniques

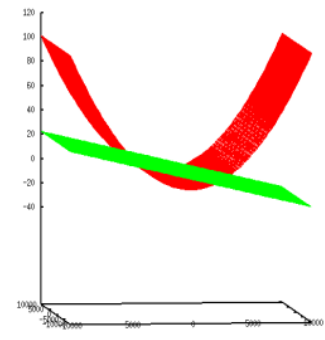

(b) Exact solutions
Figure 2: Profiles of the initial water surface.

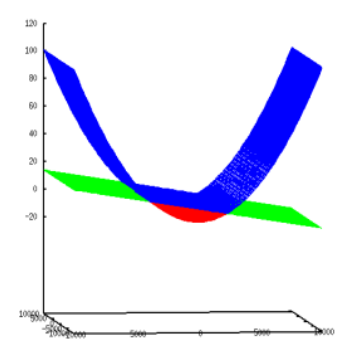

(a) $t=200 \mathrm{sec}$.

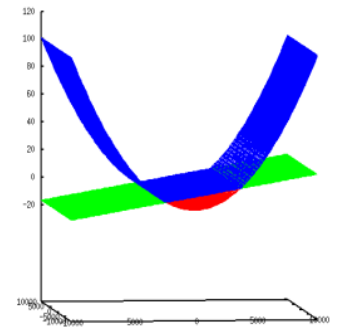

(c) $t=600 \mathrm{sec}$.

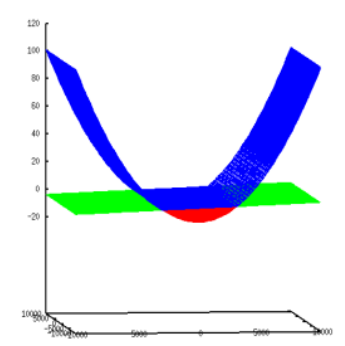

(b) $t=400 \mathrm{sec}$.

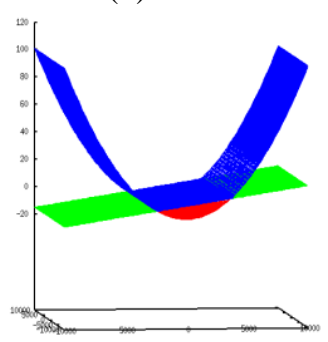

(d) $t=800 \mathrm{sec}$.
Figure 3: Comparison between numerical techniques and exact solutions of the water surface profiles.

\section{Simulation of the Mentawai 2010 Tsunami}

\section{A. Topography Data and Initial Source}

Previously mentioned numerical techniques were applied to the Mentawai 2010 tsunami event. Topographical data were obtained from British Oceanographic Data Centre (BODC), General Bathymetric Chart of the Oceans (GEBCO) One Minute Grid (GRIDONE) [12], stretched from $85.0^{\circ} \mathrm{E}$ to $106.0^{\circ} \mathrm{E}$ and $6.0^{\circ} \mathrm{N}$ to $15.0^{\circ} \mathrm{S}$. The data provided in the form of longitude, latitude and depth were transformed into projected coordinates $x, y$, and $z$ by means of the Gauss-Krüger projection. A rectangular grid was set by dividing each side of a rectangle into 1260 subintervals. Each rectangle was divided into 2 triangles, and a triangular mesh with 1590121 nodes and 3175200 elements were set.

The initial water surface displacement calculation based on Okada [13]-[14] was set for an initial condition to compute tsunami wave propagation. Okada formulation requires nine parameters concerning the source fault plane, i.e., longitude, latitude, length, width, and depth of the source fault plane, strike angle, rake angle, dip angle, and slip amount distribution. We utilize a source fault plane which lies at $99.86567^{\circ} \mathrm{E}$ to $100.10976^{\circ} \mathrm{E}$ and $2.55268^{\circ} \mathrm{S}$ to $4.34144^{\circ} \mathrm{S}$, and divides into 28 sub-faults with $30 \mathrm{~km}$ length and $30 \mathrm{~km}$ width. The dip angle was set to $7.5^{\circ}-12^{\circ}$. The strike angle and rake angle were set to $326^{\circ}$ and $101^{\circ}$, respectively. The slip amount distribution range from $0.0 \mathrm{~m}$ to $6.10 \mathrm{~m}$ [4]. The resultant of the calculation show that the maximum water surface displacement of these 28 sub-faults was up to $3 \mathrm{~m}$ and located near Pagai island (sub-fault 4) [7].

\section{B. Simulation Results}

Tsunami waves propagation were simulated for 3600 seconds or 1 hour from the first initial wave generated. The initial surface displacement of 28 sub-faults described in the previous subsection was shown in Fig. 4. At the time prior to 600 seconds (or 10 min.), as shown in Fig. 5 (a) and Fig. 6, the initial waves were ruptured, propagated and reached the shoreline area. Similar results were also obtained by Mikami et.al. [15], stated that the first tsunami wave arrived 10-20 min. after the earthquake occurred. The resultants were yields from the numerical techniques using linear shallow water equations, solved by the finite-difference method with a leap-frog scheme.

Moreover, the resultants of tsunami waves arriving time also confirmed by witnesses of the Mentawai 2010 earthquake and tsunami field survey by Hill et.al. [16], which reported the time interval between the earthquake and first peak tsunami wave was between five to ten minutes. The Indonesia Meteorological, Climatological, and Geophysical Agencies (BMKG) issued a national warning for a local tsunami five minutes after the earthquake [4]. Fig. 5 (b), (c), (d), (e) and (f) show the waves propagation at 1200 seconds of simulation, while the next figure shows the waves propagation for 1800 seconds, 2400 seconds, 3000 seconds and 3600 secods of simulations, respectively.

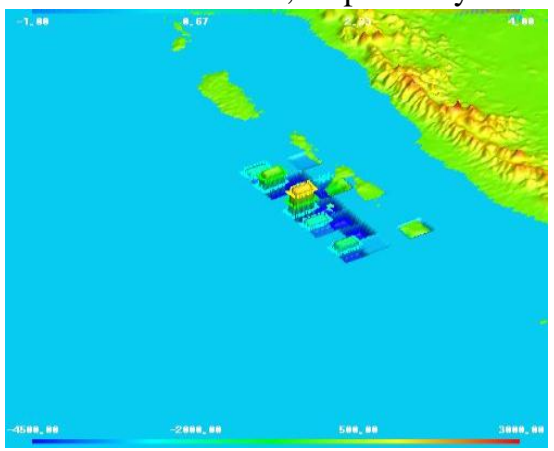

Figure 4: Initial surface displacement of Mentawai 2010 tsunami at 0 second. 
Proc. of The Seventh Intl. Conf. on Advances in Civil, Structural and Environmental Engineering - ACSEE 2018

Copyright (C) Institute of Research Engineers and Doctors, USA. All rights reserved.

ISBN: 978-1-63248-158-0 doi: 10.15224/978-1-63248-158-0-28

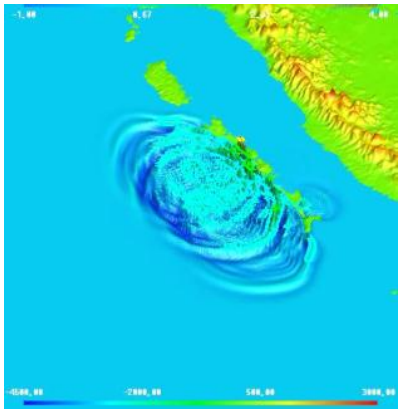

(a) $600 \mathrm{sec}$.

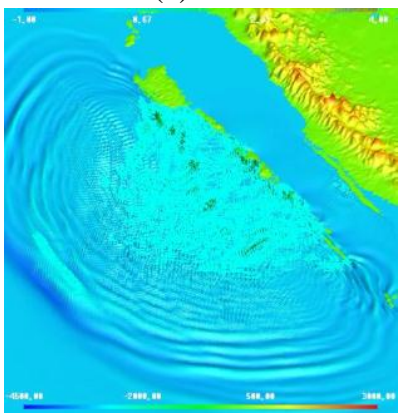

(c) $1800 \mathrm{sec}$.

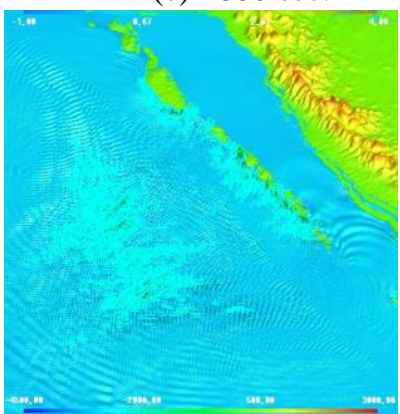

(e) $3000 \mathrm{sec}$.

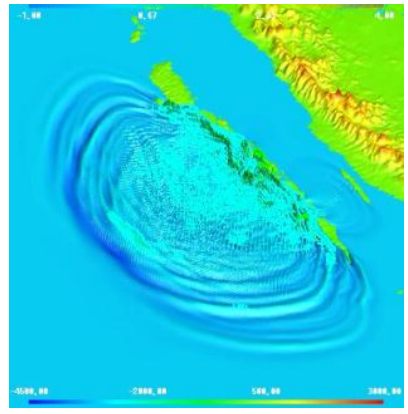

(b) $1200 \mathrm{sec}$.

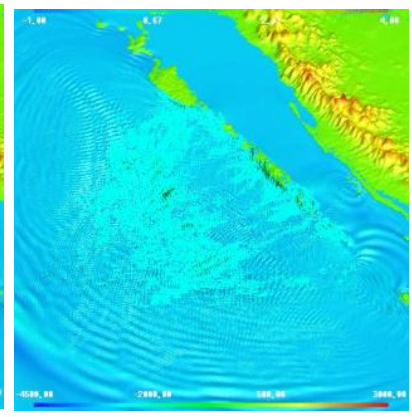

(d) $2400 \mathrm{sec}$.

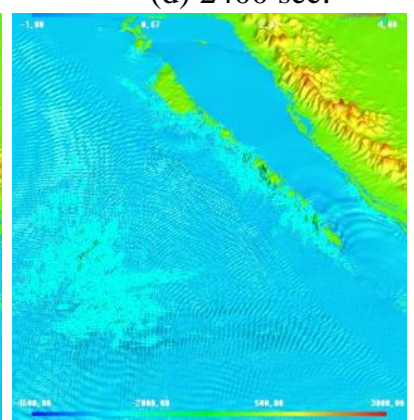

(f) $3600 \mathrm{sec}$.
Figure 5: Wave propagation of the Metawai 2010 tsunami.

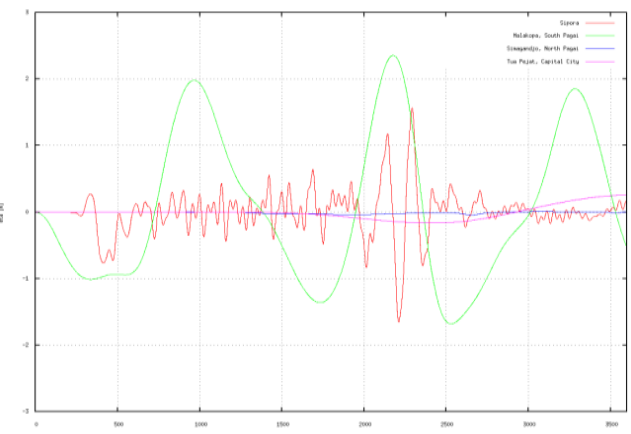

Figure 6: Wave height changes at several points in the Mentawai Islands.

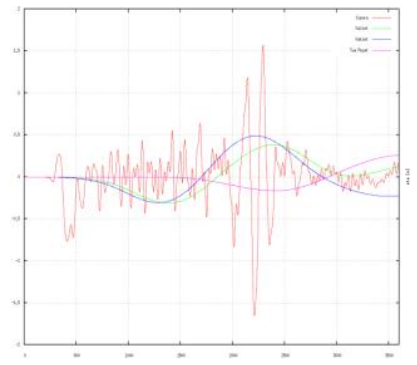

(a) Sipora Islands

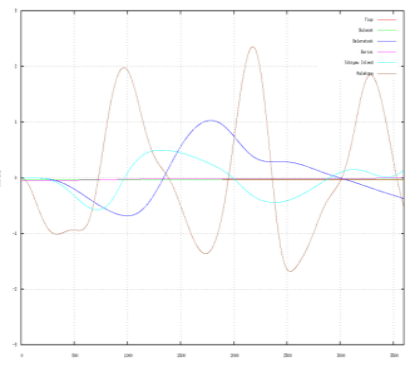

(b) South Pagai Islands
Figure 7: Tsunami wave height transition.
The computed tsunami heights produced $\sim 3 \mathrm{~m}$ waves occurred at the shoreline of South Pagai island (Fig. 6) at the time $>2000$ seconds. Waves with $\sim 2 \mathrm{~m}$ height occurred at the shoreline of South Pagai island at the time $500<$ $t<1500$ seconds and $3000<t<3500$ seconds. We take several points at the Mentawai islands to see the wave height level and presents it in Fig. 6. Point 1 is at the Sipora area, has the highest wave level greater than $1 \mathrm{~m}$. Point 2 is at Malakopa, one area of the South Pagai islands have the maimum wave height $\sim 3 \mathrm{~m}$. Whereas, at the other two points Simagandjo, North Pagai islands and Tua Pejat, the capital city of Mentawai Islands Regency, there is no significant water displacement appears.

Fig. 8 shows the comparison between tide gauge station data and numerical results for one and a half hours simulation. Tide gauge data were obtained from the United Nations Educational, Scientific and Cultural Organization (UNESCO), Intergovernmental Oceanographic Commission (IOC), Sea Level Station Monitoring Facility website [17]. Those data were per 60 seconds data. Fig. 8 show tide gauge data from 21:42 WIB (Western Indonesian Time) to 23:12 WIB. Three tide gauge station near the Mentawai Regency areas, i.e. Tanahbala station, Teluk Dalam station and Enggano station were chosen. Tide gauge station of Tanahbala located at $98.5^{\circ} \mathrm{E}$ and $0.53^{\circ} \mathrm{N}$, while the coordinate of the numerical results was at $98.5000^{\circ} \mathrm{E}$ and $0.5333^{\circ} \mathrm{N}$. Whereas, Teluk Dalam station located at $97.822^{\circ} \mathrm{E}$ and $0.554^{\circ} \mathrm{S}$, and the numerical results was at $97.8167^{\circ} \mathrm{E}$ and $0.5500^{\circ} \mathrm{S}$. Enggano station located at $102.2781^{\circ} \mathrm{E}$ and $5.3461^{\circ} \mathrm{N}$, and the numerical results was at $102.2833^{\circ} \mathrm{E}$ and $5.3500^{\circ} \mathrm{N}$.

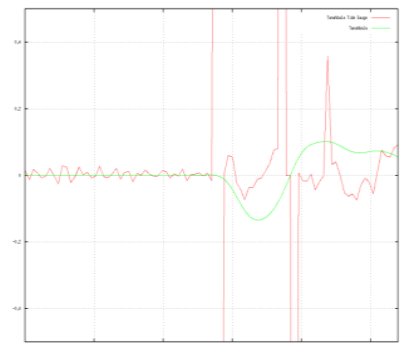

(a) Tanahbala station

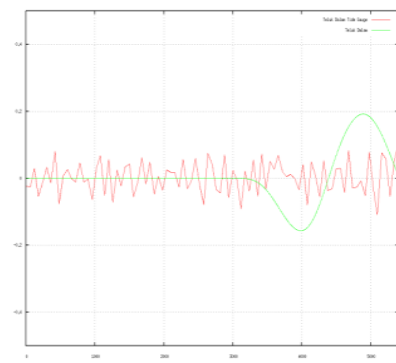

(b) Teluk Dalam station

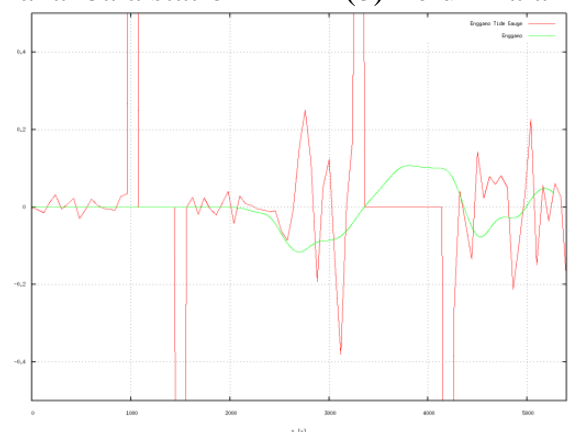

(c) Enggano station

Figure 8: Wave height changes comparison between Tide Gauge data and numerical results. 
Proc. of The Seventh Intl. Conf. on Advances in Civil, Structural and Environmental Engineering - ACSEE 2018

Copyright (C) Institute of Research Engineers and Doctors, USA. All rights reserved.

ISBN: 978-1-63248-158-0 doi: 10.15224/978-1-63248-158-0-28

\section{v. Simulation of the Indian Ocean 2004 Tsunami}

\section{A. Topography Data and Initial Source}

Topographical data from British Oceanographic Data Centre (BODC), General Bathymetric Chart of the Oceans (GEBCO) One Minute Grid (GRIDONE) [12] were utilized for the Indian Ocean 2004 tsunami. It stretched from $75.0^{\circ} \mathrm{E}$ to $103.0^{\circ} \mathrm{E}$ and $10.0^{\circ} \mathrm{N}$ to $18.0^{\circ} \mathrm{S}$. The Gauss-Krüger projection was applied to the data. A triangular mesh with 2825761 nodes and 5644800 elements was produced by dividing each side of a rectangle into 1680 subinterval and dividing each of subrectangle into two triangles.

The initial water surface displacement based on Okada formula [13],[14] was generated for an initial condition. The source surface displacement of the Indian Ocean 2004 tsunami consisting of 22 sub-faults lies from $91.51^{\circ} \mathrm{E}$ to $96.23^{\circ} \mathrm{E}$ and $1.75^{\circ} \mathrm{N}$ to $13.51^{\circ} \mathrm{N}$. The dip angle was set to $10^{\circ}$, values of the strike angle ranged from $0^{\circ}$ to $350^{\circ}$, values of the rake angle ranged from $85^{\circ}$ to $130^{\circ}$, and values of the slip amount distribution ranged from $0.1 \mathrm{~m}$ to $30.3 \mathrm{~m}$ [2]. The maximum water surface displacement height was approximately $20 \mathrm{~m}$ (Fig. 9).

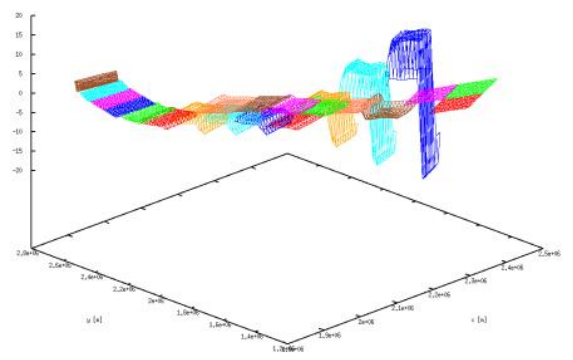

Figure 9: The initial water surface displacement for 22 sub-faults.

\section{B. Simulation Results}

The Indian Ocean 2004 tsunami was simulated for the first 5400 seonds or 1.5 hours. The initial waves were collapsed and reached the shoreline area after five to fifteen minutes after the earthquake. Syamsidik et. al. [18] reported the arriving times of tsunami waves after the earthquake at several areas in Aceh Province, 22 min. at Sabang, 35 min. at Banda Aceh, 25-62 min. at Lageun, 29-72 min. at Calang, 29-72 min. at Teunom, 24-37 min. at Tapaktuan, and $53 \mathrm{~min}$. at Singkil. Meanwhile, our numerical results show that the first tsunami waves reached shoreline of Aceh Province after 50 min. at Banda Aceh, Lageun, Singkil, and Calang. The initial tsunami waves reached shoreline area of Sabang at 33 min. after the earthquake, whereas the first tsunami wave approached the shoreline areas of Teunom and Tapaktuan at 1 min. after the earthquake (Fig. 11).

Fig. 12 show profile of the water surface displacement of the Indian Ocean 2004 tsunami. Note that most of the source faults were occured in the vicinity of the Aceh Province area. Three sub-faults with the maximum water surface displacement were generated at the west coast of the Aceh Province. Fig. 13 (a)-(h) displays tsunami wave propagation of the Indian Ocean 2004 tsunami at 600 seconds, 1200 seconds, 1800 seconds, 2400 seconds, 3000 seconds, 3600 seconds, 4200 seconds, and 4800 seconds, respectively. In the simulation, the maximum wave height was set to $30 \mathrm{~m}$, that is, the wave height was set at $30 \mathrm{~m}$ when it exceeds $30 \mathrm{~m}$.

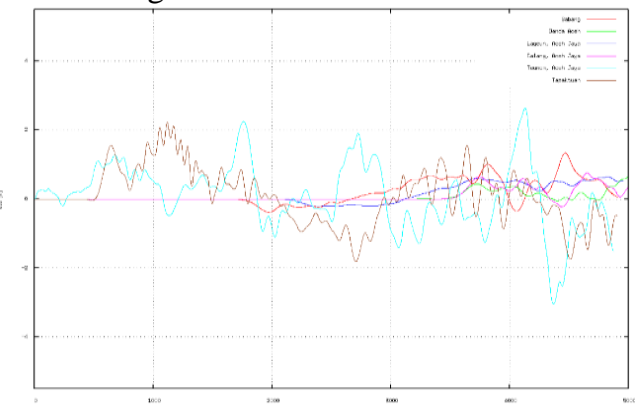

Figure 10: Wave height changes at several points in the Aceh Province, Indonesia.

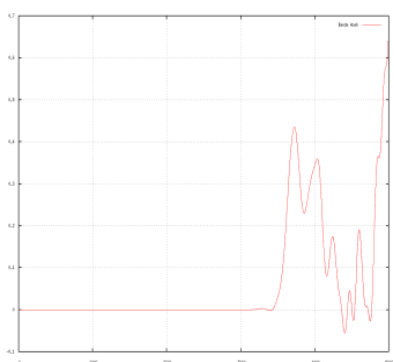

(a) Banda Aceh

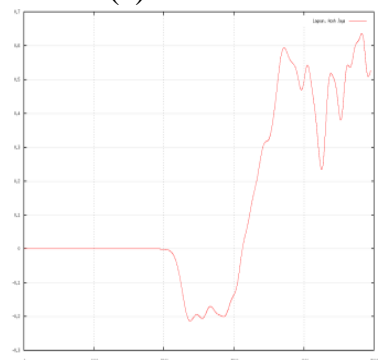

(c) Lageun

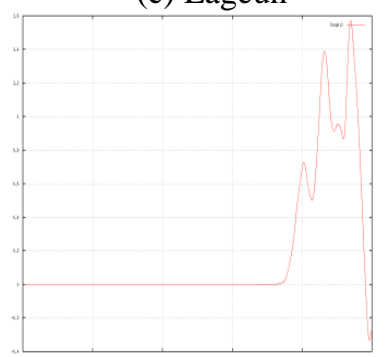

(e) Singkil

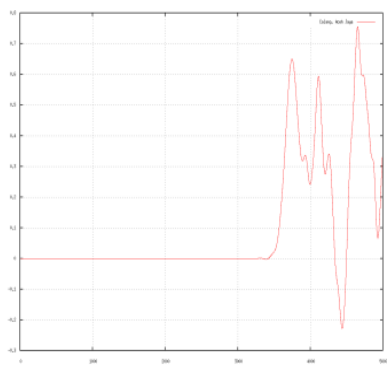

(b) Calang

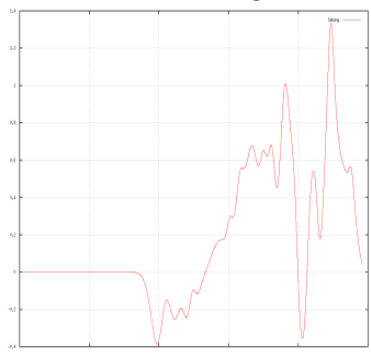

(d) Sabang

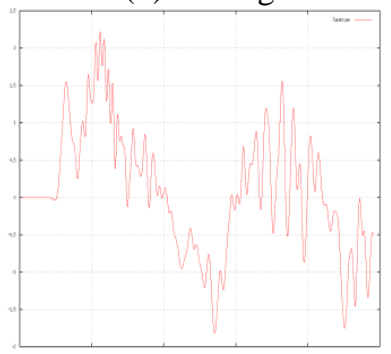

(f) Tapaktuan 
Proc. of The Seventh Intl. Conf. on Advances in Civil, Structural and Environmental Engineering - ACSEE 2018

Copyright (C) Institute of Research Engineers and Doctors, USA. All rights reserved.

ISBN: 978-1-63248-158-0 doi: 10.15224/978-1-63248-158-0-28

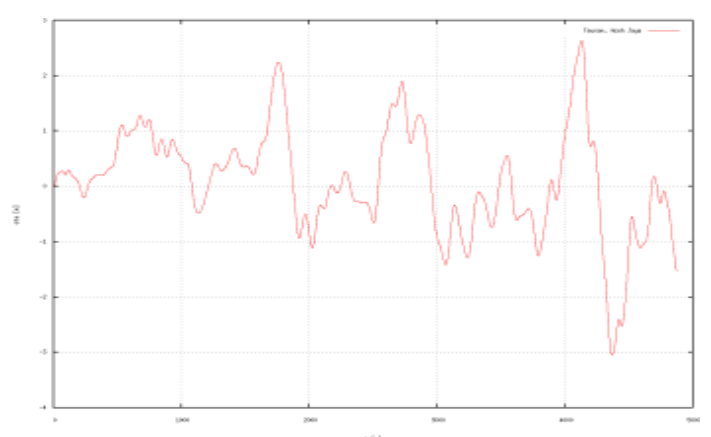

(g) Teunom

Figure 11: Tsunami wave height transition.

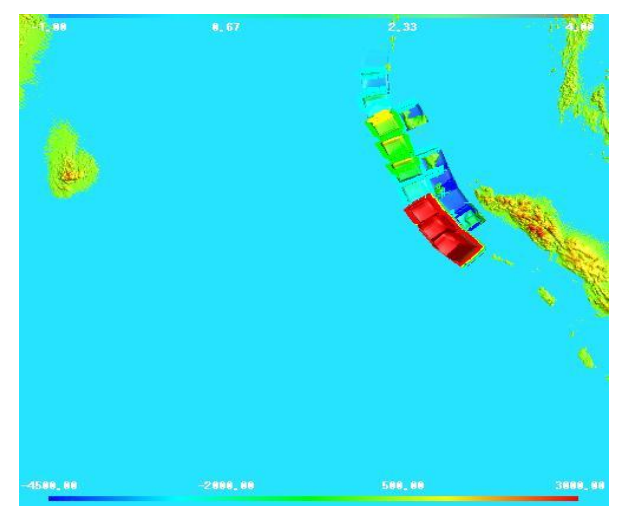

Figure 12: The initial surface displacement of the Indian Ocean 2004 tsunami.

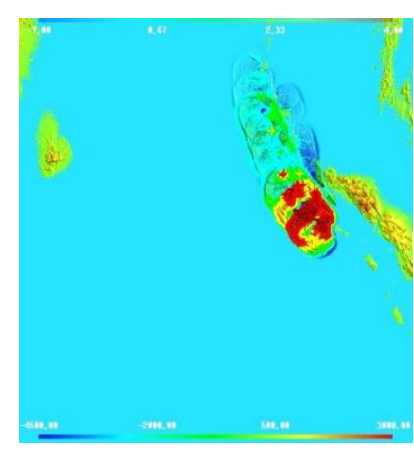

(a) $600 \mathrm{sec}$

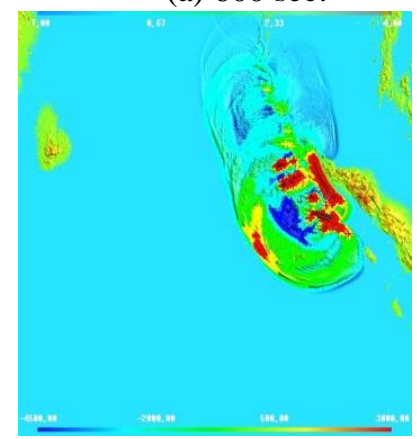

(c) $1800 \mathrm{sec}$.

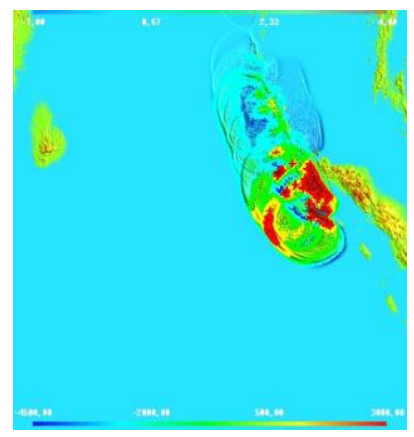

(b) $1200 \mathrm{sec}$.

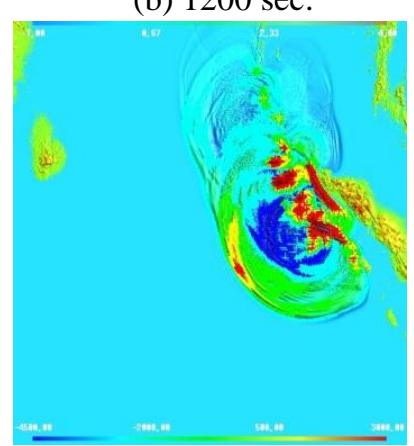

(d) $2400 \mathrm{sec}$.

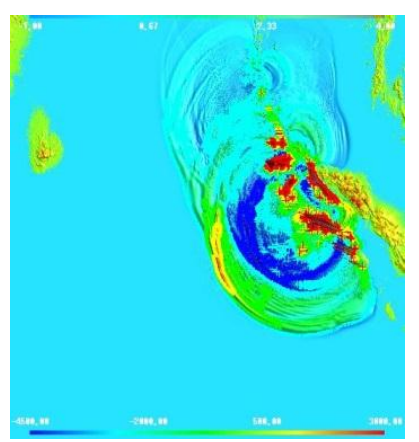

(e) $3000 \mathrm{sec}$.

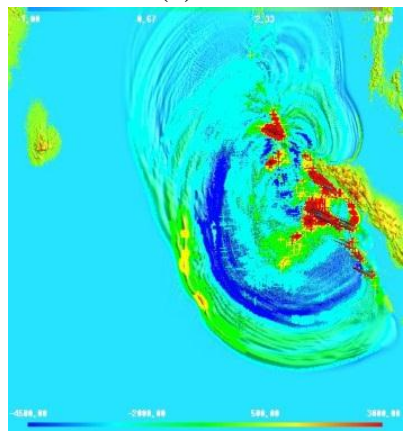

(g) $4200 \mathrm{sec}$.

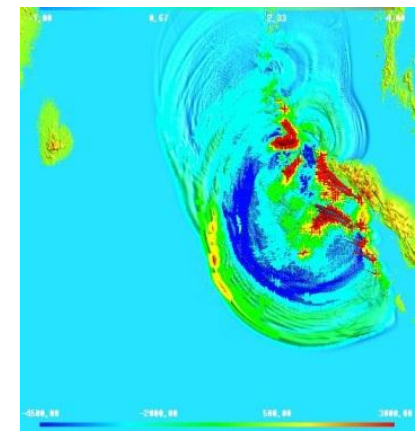

(f) $3600 \mathrm{sec}$.

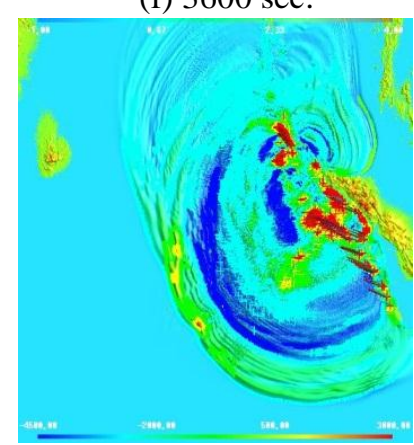

(h) $4800 \mathrm{sec}$.

Figure 13: Wave propagation of the Indian Ocean 2004 tsunami.

\section{vI. Conclusion}

The Mentawai Islands 2010 tsunami and the Indian Ocean 2004 tsunami were simulated with the application of moving shoreline techniques. Our numerical techniques were tested with comparison between the exact solution and the numerical of the two-dimensional nonlinear shallow water equations for flow above parabolic bottom topography. Fig. 3 shows an acceptable agreement between the numerical solution and the exact solution for the first 800 seconds. Further studies are necessary to solve the uncontrollability of numerical solutions for $t>800$ seconds.

Tsunami waves propagation of the Mentawai islands on October 2010 were simulated for one hour after the first initial wave was generated. Our numerical results show that the initial waves collapsed, and that the first waves reached the shoreline areas of the Mentawai Islands at $10 \mathrm{~min}$. after the earthquake. Tsunami wave height transition was obtained at several points (Fig. 6).

The Indian Ocean 2004 tsunami was simulated for one and a half hours after the generation of the initial wave. Our numerical results show that the initial waves collapsed, and that the first waves approached the shoreline area of the Aceh Province at 5-50 min. after its generation. Tsunami wave height level was observed at several points in the Aceh Province (Fig. 13).

A tsunami is an event that can bring a devastating destruction, and it is important to develop a network based tsunami early warning system. Our techniques will hopefully contribute to establishment of the system.

\section{Acknowledgment}

The authors thank Dr. Kazuhiro Yamamoto for his technical assistance. 
Proc. of The Seventh Intl. Conf. on Advances in Civil, Structural and Environmental Engineering - ACSEE 2018

Copyright (C) Institute of Research Engineers and Doctors, USA. All rights reserved.

ISBN: 978-1-63248-158-0 doi: 10.15224/978-1-63248-158-0-28

\section{References}

[1] F. Cap, "Tsunamis and hurricanes, a mathematical approach," Springer-Verlag/Wien, 2006.

[2] Y. Fujii, K. Satake, "Tsunami source of the 2004 Sumatra-Andaman earthquake inferred from tide gauge and satellite data," Bulletin of the Society of America, vol. 97, no. 1A, pp. S192-S207, January 2007.

[3] C. J. Ammon, T. Lay, H. Kanamori, M. Cleveland, "A rupture model of the 2011 off the Pacific coast of Tohoku earthquake," Earth Planets Space, vol. 63, pp. 693-696, 2011.

[4] K. Satake, Y. Nishimura, P. S. Putra, A. R. Gusman, H. Sunendar, Y. Fujii, et.al., "Tsunami source of the 2010 Mentawai, Indonesia earthquake inferred from tsunami field survey and waveform modeling," Pure Applied Geophysics, vol. 170, pp. 1567-1582, 2013.

[5] J. Sampson, A. Easton, M. Singh, "Moving boundary shallow water flow above parabolic bottom topography," ANZIAM J.47 (EMAC 2005), pp. C373-C387, 2006.

[6] J. Sampson, A. Easton, M. Singh, "A new moving boundary shallow water wave equation numerical model,” ANZIAM J.48 (CTAC 2006), pp. C605-C617, 2007.

[7] N. Alfiany, K. Yamamoto, M. Watanabe, "Numerical study of tsunami propagation in Mentawai Island West Sumatra," Universal Journal of Geoscience, vol. 5, no. 4, pp. 112-116, 2017.

[8] F. Imamura, A. C. Yalciner, G. Ozyurt, C. Goto, Y. Ogawa, "Tsunami modeling manual (TUNAMI model)," IUGG/IOC Time Project, IOC Manuals and Guides No. 35, UNESCO, 1997.

[9] J. N. Reddy, "An introduction to the finite element method," McGrawHill Book Company, 1984.

[10] J. D. Lambert, "Computational methods in ordinary differential equations," John Wiley \& Sons, 1973.

[11] C. B. Vreugdenhil, "Numerical methods for shallow-water flow," Kluwer Academic Publisher, 1998.

[12] British Oceanographic Data Centre (BODC), Natural Environmental Research Council, General Bathymetric Chart of the Ocean (GEBCO), https://www.bodc.ac.uk/data/hosted_data_systems/gebco_gridded_bat hymetry_data/.

[13] Y. Okada, "Surface deformation due to shear and tensile faults in a half-space," Bulletin of the Seismological Society of America, vol. 75, no. 4, pp. 1135-1154, 1985.

[14] Y. Okada, "Internal deformation due to shear and tensile faults in a half-space," Bulletin of the Seismological Society of America, vol. 82, no. 2, pp. 1018-1040, 1992.

[15] T. Mikami, T. Shibayama, M. Esteban, K. Ohira, J. Sasaki, T. Suzuki, et.al., "Tsunami vulnerability evaluation in the Mentawai islands based on the field survey of the 2010 tsunami," Natural Hazard, vol. 71, pp. 851-870, 2014.

[16] E. M. Hill, J. C. Borrero, Z. Huang, Q. Qiu, P. Banerjee, D. H. Natawidjaja, et.al., "The $2010 \mathrm{M}_{\mathrm{w}} 7.8$ Mentawai earthquake: very shallow source of a rare tsunami earthquake determined from tsunami field survey and near-field GPS data," Journal of Geophysical Research, vol. 117, B06402, 2012.

[17] United Nations Educational, Scientific and Cultural Organization (UNESCO), Intergovernmental Oceanographic Commission (IOC), Sea Level Station Monitoring Facility, http://www.iocsealevelmonitoring.org/.

[18] Syamsidik, T. M. Rasyif, S. Kato, "Development of accurate tsunami estimated times of arrival for tsunami-prone cities in Aceh, Indonesia," International Journal of Disaster Risk Reduction, vol. 14, pp. 403-410, 2015.

\section{About Author (s):}
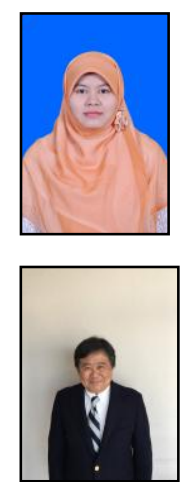

[Okayama University, Japan.]
[Graduate School of Environmental and Life Science, Okayama University, Japan.] 